\title{
Distant Technologies in Teaching Legal Disciplines to Students of Pedagogical Training Programs
}

\author{
Maxim R. Moskalenko ${ }^{1 *}$, Olga A. Tolstykh ${ }^{1}$, Evgenij M. Dorozhkin ${ }^{1}$, Matvey D. Shcherbin ${ }^{1}$, \\ Vera K. Vlasova ${ }^{2}$ \\ ${ }^{1}$ Russian State Vocational Pedagogical University, Ekaterinburg, RUSSIA \\ ${ }^{2}$ Kazan (Volga region) Federal University, Kazan, RUSSIA
}

Received 2 August 2018 - Revised 16 November 2018 - Accepted 19 December 2018

\begin{abstract}
The relevance of the studied problem is caused by the need to improve the methodology of legal disciplines teaching for students of pedagogical training programs and the need to develop the methods and forms of application of distant technologies of teaching in this process. The article is aimed at studying the opportunities of distant technologies for improvement of assimilation quality of training material for legal disciplines by students of pedagogical training programs, in particular when studying a number of key questions of interobject character. Topical issues of teaching legal disciplines for students of higher education institutions of pedagogical professions, first of all, for future teachers of social science and law are considered. The leading method of research of this problem is the pedagogical analysis of methods and forms of the use of distant technologies of teaching legal disciplines. The results of the research are the following: the carried-out analysis of the opportunities to use distant technologies of tutoring in teaching legal disciplines for students of pedagogical training program; identification of key topical issues which arise when studying legal disciplines by future teachers; the developed recommendations about improvement of training of students of pedagogical training programs. The materials of the article can be useful for: the faculty of higher education institutions which are engaged in teaching the students of the pedagogical training programs; students and graduate students of the pedagogical training programs; for teachers, in particular young specialists; for the heads of higher education institutions that have pedagogical directions of students training; to methodologists who are engaged in curriculum development for students of pedagogical training program.
\end{abstract}

Keywords: distant technologies of teaching, pedagogical training program of students, teaching legal disciplines

\section{INTRODUCTION}

The issues of improving the quality of training of students of pedagogical courses always were and are relevant in pedagogical science. Many employers (directors of schools and specialized secondary educational institutions) would like to receive young specialist who would own technologies of communication with pupils as well as efficient tutoring, skills of teaching and educational work, knowledge of main topical problem aspects of teaching their subject and abilities to solve them in practice. These data to a large extent define the quality of training of a specialist in pedagogical and professional pedagogical education (Davydova, Dorozhkin \& Fedorov, 2016, 2018; Dorozhkin \& Zeer, 2014; Dorozhkin, Kopnov \& Romantsev, 2015; Hurst, 2017; Tkacheva, Simonova \& Matveev, 2016).

(C) 2019 by the authors; licensee Modestum Ltd., UK. This article is an open access article distributed under the terms and conditions of the Creative Commons Attribution License (http://creativecommons.org/licenses/by/4.0/). \max.rus.76@mail.ru (*Correspondence) $\square$ olga.tolstyh@rsvpu.ru $\square$ evgeniy.dorozhkin@rsvpu.ru 


\section{Contribution of this paper to the literature}

- The authors revealed the problem of the relationship of teaching legal disciplines to future teachers and their successful professional activities.

- The article proves that remote technologies allow to improve the quality of mastering educational material on legal disciplines for students of pedagogical specialties, provide an opportunity to consider the most frequent situations in their future professional activity and the use of legal norms when resolving them.

- The results of the study indicate the need for the introduction of distance learning technologies in order to improve the quality of teaching legal disciplines for students of pedagogical areas of training. This is especially relevant, since the concept of a legal state itself implies the development of the legal culture of both schoolchildren and teachers, as well as the ability of practical resolution by legal means of various controversial situations encountered in working with students at school.

Adoption of legal subject matters is of great importance for formation of competences which future teacher has to own. Especially it concerns future teachers of social science and law and on the whole the legal disciplines are important for students of pedagogical specialties (Hurst \& Hurrell, 2016). The concept of development of constitutional state in Russia assumes the strong and active education of legal culture of school students both in educational, and in extra-curricular work (Gimaliev et al., 2018). It is natural that future teachers have to own technologies of legal education of school students and prevention of their infringing activity.

In teaching legal disciplines there are issues of combining traditional methods of teaching with the use of distant technologies. Technologies of distant teaching with the use of the Internet and the electronic educational environment are more and more widely applied in the modern higher education. Distant technologies are designed to increase effectiveness and individualization of teaching students (Arenkina, 2015).

All the above mentioned makes the problem of effective use of distant teaching technologies in teaching legal disciplines for students of pedagogical training programs very relevant.

There is rather large number of researches on various aspects of the use of distant teaching technologies in training students of pedagogical training program and also of teaching legal disciplines. It is possible to mark the researches of such authors as (Alyokhin \& Lazukin, 2016; Davydova, 2016; Degil \& Kostyukova, 2016; Golovkin, 2013; Gunibsky, 2014; Gura, 2007; Malysheva, 2015; Mashinyan \& Kochergina, 2016; Mutavchi et al., 2018; Polat, Moiseyeva \& Petrov, 2006; Ryabchenko et al., 2018; Turanin \& Pogorelov, 2016) and some others.

In these works some problem points are insufficiently developed, namely:

- issues of effectiveness of the use of distant teaching technologies in training students of pedagogical training programs;

- specifics of legal knowledge development of minors in Russia and also features of the concept of legal education of school students;

- issues of training of future teachers by methods of using reconstructive technologies and mediation in the conflicts with participation of minors;

- issues of combination of distant and traditional methods of teaching of legal disciplines to students of pedagogical training program.

The scientific novelty, theoretical and practical significance of this work is to study the mentioned matters.

In foreign pedagogics when training pupils of pedagogical specialties distant technologies of teaching and electronic educational resources are used rather widely and provide teaching individualization (Arenkina et al., 2015). At the same time, searching of a harmonious combination of distant technologies and immediate communication with the teacher as the specifics of teachers training assume broad development of communicative and oratorical skills, knowledge of technologies of audience management and classes conducting. Development of these competences is impossible without personal contact of students with teachers of the most various disciplines and also the active work of tutors (Nesterenko \& Matviyenko, 2016). In many foreign higher education institutions distant technologies of post-degree education are also widely applied (Buhanova et al., 2015).

\section{MATERIALS AND METHODS}

\section{Research Techniques}

The principles and methods comprise the basis of the research:

1. The analysis of methods and forms of use of distant technologies of teaching when teaching legal disciplines to the students of pedagogical training program. 
2. The pedagogical analysis of the main problem aspects arising during adoption of legal disciplines by students of the pedagogical training program.

3. Identification and synthesis of authors' pedagogical work experience in teaching legal disciplines to students of pedagogical training programs.

4. Systemacities, allowing revealing key issues which future teachers have to acquire in the course of studying of legal disciplines to increase the effectiveness of their preparation for practical work with school students.

\section{The Experimental Base of the Research}

The trial resources of the research include: studying the methods and forms to use distant technologies of teaching in Russian State Vocational Pedagogical University (Ekaterinburg city) and Kazan (Volga region) Federal University (Kazan city); pedagogical observation and the analysis of using various elements of distant educational technologies in teaching work of authors with students.

\section{Investigation Stages}

The research was carried out in three stages:

1. Studying of the place and the role of distant technologies of teaching in training the students of pedagogical specialties.

2. Identification of the problem aspects of applied and theoretical character arising in teaching legal disciplines to students of pedagogical specialties.

3. Analysis of opportunities of distant technologies of training for improvement of teaching legal disciplines in students of pedagogical specialties.

\section{RESULTS}

\section{Specifics of Teaching Legal Disciplines with the Use of Distant Technologies of Teaching}

Distant technologies of teaching started rather actively being used in the educational process of most Russian higher education institutions in the 1990th. At present the legal basis for their use is the law "On Education in the Russian Federation" dd 29.12.2012 No. 273-FZ in which in article 16 the implementation of educational programs with the application of electronic teaching and distant educational technologies is regulated.

At present the search of an optimum combination of distant technologies of teaching and traditional forms is conducted in teaching methodology of practically all subjects. The penetration of informational technologies into all spheres of activity of the modern society demands further development of the electronic educational environment. There are questions of methodological character namely: how to improve the explanation to pupils of these or those problem aspects of the course, in particular those ones having cross-disciplinary character, using the possibilities of modern distant technologies and the electronic educational environment?

Teaching legal disciplines to students of pedagogical specialties has its specifics, connected with the features of their vocational training for work at comprehensive high school and secondary vocational education institutions.

First of all, students have to own not only the knowledge of the current legislation and practical skills of its application in daily life (as when preparing in the legal directions), but also pedagogical competences of teaching school students, development of their legal culture and knowledge of prevention of infringing activity of minors. The appropriate informational resources have to be chosen by the teacher and are placed in the electronic educational environment.

Secondly, future teachers have to know problem aspects of development of legal knowledge of students of various age groups; it is good to own the theory and the technique of teaching law. The importance of this aspect is defined by a high role of a teacher in formation of legal culture of school students (Fabrikov, 2015). Here the placement of theoretical materials in the electronic environment, and then discussion of problematic issues with pupils at classes (when they already get acquainted with material) and also in the online mode or at a videoconference is possible.

Thirdly, from all the variety of literature on teaching legal disciplines the teacher should choose those works which are of the greatest scientific and practical value and recommend them to students. Here one of problematic issues is that some works on teaching law to school students are written on the basis of the western experience and are just a little adapted to the Russian conditions. The electronic educational environment gives the chance of broad access to the literature recommended by the teacher for students. 
Fourthly, practical work of students with the pupils of schools is of great importance. In the electronic educational environment different recommendations and methodological guidelines about practical training and also various training video records etc. can be placed. By means of communication on an Internet chat students can quickly discuss with the teacher the arising issues and difficulties during their practical training and to receive some recommendations. Also classes in an expanded form with the participation of the students undertaking practical work, young specialists, experienced teachers with a long standing of work and the teacher of higher education institution in an online format on exchanging of pedagogical work experience. It is natural that the time of such consultations and their format has to be coordinated in advance.

In the electronic educational environment it is good to place theoretical material on legal disciplines, the various presentations and video courses, also references to documentaries of the corresponding subject (for example, stories about well-known trials, activity of law enforcement agencies etc.) and also methodical literature for preparation for a practical training. It is also possible to conduct a part of practical training in the form of discussion, colloquium on some legal issues and also presentation of students' researches (online when the audience and the teacher have the opportunity to ask questions about the work subject). The distant format of communication also allows answering students questions, to carry out monitoring of knowledge in the form of testing, to check specially developed homework etc. When realizing these conditions the introduction of distant educational technologies in the educational process considerably expands didactic, informational, methodical and technological capabilities of pedagogical activity and promotes increase in the effectiveness of education (Lomovtseva, Tchubarkova \& Karasik, 2013).

\section{Problem and Theoretical Issues in Studying Legal Disciplines}

Except methodological questions of the use of distant training technologies to for teaching legal disciplines to future teachers, there are also problems and theoretical issues in their studying on competent understanding of which the quality of future law teachers training in many respects depends.

First, a future teacher (in particular the teacher of social science and law) has to have knowledge, abilities, possession of prevention of infringing activity of minors as the activity of pedagogical school staff in this direction is very important (Ozhiganova, Moskalenko \& Bolgova, 2016). Therefore students have to understand legibly the set of factors, which influence minors criminalization and complicating work on prevention of their infringing activity: the influence of family and close environment of a child; instigation from adult criminals; social embitterment and low level of household culture of the part of population; rather low effectiveness of the activity of prevention system of offenses of minors; rather larger hidden children's neglect caused by the fact that most of Russians work overtime up to 3-4 hours over the norm almost daily and have no enough time for communication with children; and some other circumstances.

The analysis of these factors allows giving systemic vision of the reasons of infringing activity of minors and promotes the formation of skills of teaching-preventive work with children with future teachers.

Secondly, the teacher has to own the methods of the use of reconstructive technologies and mediations in the conflicts with participation of minors; to know the legislative base of conducting mediation procedures and to be able to carry out this activity in practice, in particular, in work of school services of reconciliation and consent. Development of these skills in teaching legal disciplines is one of priority (Ivanova, 2014).

Thirdly, students should to have the idea that development of legal culture of school students considerably goes ahead their moral maturity. There are situations when some pupils begin to use the knowledge of legal norms, first of all, for rendering pressure upon teachers, and sometimes for mockering at them. We should mention that it is about a rather small group of school students, first of all, so-called "at-risk student" who sometimes seek to raise the authority among agemates, opposing themselves to the teacher and throwing down a challenge to the standards of behavior.

It is necessary to mention that at the time of the USSR similar problems practically did not arise. First, rather serious educational impact was made by ideology which proclaimed the main features of a Soviet person as honesty, sense of patriotism and civic consciousness, service to the Homeland. These slogans, certainly, not always coincided with reality, but were admitted as valid social ideals. It is natural, that the image of a teacher and his manner of behavior had to give representation of this ideal (that disciplined both teachers, and pupils and set particular moral standards), and the rights of the teacher for educational influence were not subject to doubt. Secondly, in society lines of traditional consciousness with its respect to the teacher as to the carrier of knowledge, scientific culture and high moral standards remained, and the social status and authority in society of the teacher and the teacher of higher education institution were rather high.

In the modern Russia the situation has changed. On the one hand, in society there is a crisis of traditional moral norms, and also development, especially among youth, hedonism and consumer relation to the society. On the other hand, rather strong sociocultural influence and pressure of underworld upon the society deforming valuable 
orientations of youth takes place (Kuleshova, 2009). All this led to the fact that in practice cases of rendering pressure upon teachers from school students appeared.

It is necessary to mention that this problem is realized by pedagogical community, and mechanisms of its solution appear as well, for example, school services of reconciliation and mediation which are aimed at solving conflict situations arising both between pupils, and between pupils and teachers are created. Activity of school services of reconciliation and mediation, certainly, is very important meaning that it forms the culture of dialogue with pupils, attaches to legal ways of conflicts solution. This activity can be considered as one of institutes of civil society development in the educational environment. But in general at the moment efficient legal mechanisms of teachers protection against pressure and rudeness of pupils do not exist.

To use distant technologies of teaching legal disciplines to the students of pedagogical training programs effectively it is necessary:

First, flexible combination of distant and traditional forms of education and also acquaintance of students with problem aspects of practical use of their knowledge. Especially it is subject to the development with the students of knowledge, abilities, possession in the theory and technique of law training, work on prevention of infringing activity of minors, skills of mediation at solution of the conflicts with participation of minors and studying of some other current problems with which students will face (or have already faced) necessarily in pedagogical activity. The mixed training on the basis of integration and the mutual addition of technologies of traditional and electronic teaching is necessary.

Secondly, the active use of electronic educational environment for adoption of theoretical training material, preparation for practical training, realizations of a number of educational tasks. The variety of training materials which can be placed in it (literature, presentations, documentaries etc.) can increase the effectiveness of the students' preparation for classical classes in internal study mode.

Thirdly, it is necessary to pay special attention to such theoretical question as development in students of comparative-legal analysis skills and also abilities to teach these skills to pupils of schools. Teaching students of methodology and conceptual bases of teaching law and social science from the position of recognition of specifics of Russia of importance (for example, strongly marked priority of social and economic rights over political ones during the Soviet period, etc.). It assumes keeping the principles of historicism (the analysis of objects of the research in connection with certain historical conditions of their existence, in dynamics of their development in time) and system approach to the studied phenomena and processes.

\section{DISCUSSIONS}

It is possible to mark out argumentative aspects of teaching to pedagogical specialties students of legal disciplines with the use of distant technologies of teaching:

The first group of argumentative questions is connected with the practical use of distant technologies in teaching.

On the one hand, in literature (Alyokhin \& Lazukin, 2016; Gunibsky, 2014; Shutova, 2016; Turanin \& Pogorelov, 2016) it is much said about the need of modernization of teaching legal disciplines, the use of the active and interactive technologies of teaching.

Among interactive forms of lecture classes we can distinguish the following: a problem lecture (the teacher at the beginning and in the course of presentation of learning material explains problem situations and involves students in their analysis); a lecture provocation (a lecture with the planned mistakes); a binary lecture (work of two teachers giving a lecture on the same subject and interacting both among themselves, and with the audience); a lecture visualization (transfer of information by the teacher to students is followed by display of various drawings, structural logical circuits, basic abstracts, charts, etc.); the lecture "press conference" (the teacher within 3-5 minutes asks students to ask him in writing the question that is interesting to each of them about the given lecture topic. Then the teacher systematizes these questions according to their contents and begins to give a lecture, including answers to the asked questions in its contents); lecture dialogue (contents is presented through a series of questions which students have to answer immediately during the lecture) (Shutova, 2016).

On the other hand, it is very little written about practical methods of conducting interactive lectures on legal disciplines using distant technologies and electronic educational environment, the issues are considered only by certain authors (Pochinalina, 2007). Now distant technologies of teaching are put into practice in many higher education institutions including RGPPU, and teachers, on the basis of work experience and the features of audience, have to select these or those forms of explanation of the material. Visualization lectures are the most often applied as the electronic educational environment creates for this purpose many opportunities or the ordinary lecture of "frontal" type, aimed at passive adoption of the material as well as lack of immediate contact with the audience reduces even more its already low effectiveness. 
On the basis of the article authors' experience, the following scheme is seemed optimal:

1. An introduction overview lecture at which the studied subject is introduced is given, the main problematic issues of the course are identified, and students are given the review of the sources which are available in the electronic educational environment for studying the subject;

2. Consultations with students on questions which they have when studying training material, fulfillment of control tasks and getting ready for practical training; consultations can is carried out with the help of the Internet chat or e-mail;

3. A series of lectures at which a number of the above described forms is applied: visualization, "press conference", dialogue.

The binary lecture is the most effective one when explaining to students the problems of cross-disciplinary character. For example, application of mediation in the conflicts with participation of minors: the teacher-lawyer and the teacher-teacher (it can be a school teacher with wide experience of work invited to online class) will tell students various visions of the question, will give the complete and whole description of the studied problem.

A lecture - provocation is applicable only if the audience is rather prepared and in general knows the subject bases, and can be applied as one of the forms of summative assessment and also for activization of cognitive activity of students.

The similar situation is the same with practical training. Various authors (Gunibsky, 2014; Petrova, 2015; Shutova, 2016) stress the importance of interactive forms of conducting practical training and their technologies are developed in details.

Among interactive forms of practical training various types of games are very effective: subject, role, business, imitating, didactic or educational (Petrova, 2015). Business game represents the imitation of a certain situation, and its purpose is the formation of professional competences. Role-playing game as a method of teaching is directed to solving a problem by searching various ways of behavior in certain situations. Pupils take the roles of other people and act in their framework. In role-playing game the pupils are usually given unfinished situations and they have to make a certain decision, solve the conflict or finish the given situation. Also didactic games, intellectual or cognitive games which have fixed rules are marked out. In didactic games the task of pupils is to mobilize the available knowledge and quickly make the decision, to show resourcefulness and as a result to win the competition. Educational court or the method of simplified judicial proceedings which allows pupils to play trial in the educational purposes can be a specific form of business or role-playing game (Petrova, 2015).

In all these games students work out the competences of two types: development of skills to use legal and pedagogical knowledge in specific conditions; possession of technologies of conducting business and role-playing games with school students of various age groups at lessons of social science, law and also of various other disciplines (as the technique is in many respects universal).

The efficient form of practical training is also preparing pedagogical projects by students with pupils of comprehensive schools, using possibilities of network interaction with the organizations of general and additional education (Belyankova \& Shchurinova, 2016).

And also, as well as in a case with lectures, there are no enough recommendations how to use distant technologies and possibilities of electronic educational environment for training in an interactive form. These matters are actually avoided.

The authors of the article assume that the considerable proportion of practical training in an interactive form is admissible in a distant format: a presentation at discussion or colloquium; written answers to problematic issues; drawing up, solving and discussion of pedagogical and legal tasks. For this purpose it is necessary that students could get acquainted with various educational and methodical materials in the electronic environment where texts, presentations, video records can be loaded. Role-playing and business games, naturally, are held in an internal format, and the preparation for them including acquaintance with the training material, setting of purposes and tasks, searching for precedents (if it is about educational court) can be conducted by pupils in the electronic educational environment.

The second group of debatable questions is connected with ambiguous estimates of labor effort of the teacher for work with the use of distant technologies.

In literature (Bagrova, 2007) it is claimed that the use of distant technologies can lower considerably the teacher's labor effort on carrying out time-consuming and routine work to prepare control tasks and to check tests, examination answers etc. and a great number of training materials in the electronic educational environment will allow students to get acquainted themselves with the material which required the teacher's explanation earlier.

Meanwhile, the experience shows that huge labor efforts of the teacher which are necessary for creation and constant improvement of methodology-pedagogical support for realization of teaching with the use of distant technologies and electronic educational environment often remain unaddressed: first of all it is the modification of 
fund of assessing means and also the selection and development of educational and methodical materials to place them in the electronic educational environment, etc. It is rather difficult to calculate these labor efforts as they depend on various factors: readiness of the teacher to work in the electronic educational environment, features of the course taught etc.

The third group of debatable questions is connected with the fact that the wide use of distant technologies in teaching assumes that its result is aimed at individual inquiries and needs of pupils (Gura, 2007), at the possibility of studying at individual speed and on flexible hours (Sivokon, 2016), meanwhile, the education system in Russia is not focused on studying process individualization. For realization of online courses it is necessary that pupils have self-discipline, independence and high organization, and not all students have these qualities. At the same time the attention rather often is not paid to a pedagogical component of distance learning (Chutorskoi, 2012). It can be summed up with difficulties of educational work with students and pedagogical impact on them.

The solution is seemed to be in a flexible combination of distant technologies with classical methods. It is necessary to apply the mixed teaching - the model made on the basis of integration and mutual adding of technologies of traditional and electronic teaching, assuming reduction of classroom hours due to transfer particular types of educational activity into electronic environment (Veledinskaya \& Dorofeyeva, 2015).

\section{CONCLUSION}

When using distant technologies of teaching in teaching legal disciplines to the students of pedagogical training programs it is necessary to present the material in the electronic educational environment correctly (material has to be various, it should include textbooks and references to scientific articles, presentations, videos etc, and at the same time it should be systematized and prepared carefully). Problem setting of questions at lectures with the subsequent consolidation of the gained knowledge at practical classes is also important: implementation of projects on given problems, preparation and conducting role-playing and business games etc. When implementing these conditions the introduction of distant educational technologies in educational process expands didactic, informational, methodical and technological opportunities of teaching and increases studying efficiency.

Materials of the article can be useful for: the faculty of higher education institutions which are engaged in training of students and graduate students of the pedagogical training programs; bachelors, undergraduates and graduate students of pedagogical training programs; to teachers, in particular young specialists; to heads of higher education institutions in which there are pedagogical directions of students training; to methodologists who are engaged in curriculum development for students of the pedagogical training programs; to students, graduate students and students of professional development who study with use of distant technologies of teaching.

In the course of the research there arose new questions and problems that need being solved. It is necessary to analyse foreign experience of teaching legal disciplines to students of pedagogical training programs, to reveal possibilities of its adaptation to the Russian educational environment. To consider in more detail the features of using distant technologies of teaching for students of intramural, mixed and extramural forms of studying and also for arranging methodical seminars with participation of students, experienced teachers, teachers of higher education institutions, representatives of education authorities, practicing lawyers and also, perhaps, parents of pupils (at their will) to discuss the problems arising in pedagogical process. In more detail to develop technologies of different-level training in legal disciplines depending on readiness of pupils, their adoption of the material and individual needs.

\section{ACKNOWLEDGEMENT}

The work is performed according to the Russian Government Program of Competitive Growth of Kazan Federal University.

\section{REFERENCES}

Alyokhin, I. A., \& Lazukin, A. D. (2016). Innovative technologies in professional and pedagogical training of teachers of legal disciplines. Law and education, 3, 4-13.

Arenkina, E. A., Babanskaya, O. M., Dubrovskaya, V. S., \& Feshchenko, A.V. (2015). Distant technologies in implementation of master programs: analysis of the experience of foreign universities. Open and distant education, 1(57), 78-86.

Bagrova, N. A. (2007). Modern methods of teaching legal science in high education institution. Retrieved from http:/ / www.pandia.ru/text/78/356/1705.php

Belyankova, E. I., \& Shchurinova, I. A. (2016). Practice-oriented approach to professional competence formation of future history and law teacher. Bulletin of Tver State University. Series: Pedagogics and psychology, 2, 158-169. 
Buhanova, N. V., Kuz'min, K. V., Petrova, L. E., \& Chemezov, S. A. (2015). Quality standards for distance learning in higher education: a comparative analysis of Canadian and Russian practices. The Education and science journal, 7, 135-151.

Chutorskoi, A. V. (2012). Is distant education of high quality possible today? Retrieved from http:/ / khutorskoy.ru/be/2012/0524/index.htm

Davydova, N. N., Dorozhkin, E. M., \& Fedorov, V. A. (2018). Educational research networks principles of organization. International Journal of Engineering and Technology (UAE), 7(2), 24-29.

Davydova, N. N., Dorozhkin, E. M., Polyanskova, N. V., \& Nuykina, E. Y. (2016). Formation of a cluster integration system of educational institutions within the region. International Journal of Environmental and Science Education, 11(16), 9206-9221.

Davydova, N. N., Dorozhkin, E. M., \& Fedorov, V. A. (2016). Innovative process developmentin the framework of scientific educational network: management model. Naukovyi Visnyk Natsionalnoho Hirnychoho Universitetu, 5, 157-163.

Degil, I. M., \& Kostyukova, T. A. (2016). Specifics of work of the teacher of high education institution in electronic educational environment. Open and distant education, 3(63), 5-10.

Dorozhkin, E. M., \& Zeer, E. F. (2014). Methodology of professional pedagogical education: theory and practice (theoretical and methodological foundations of vocational teacher education). The Education and science journal, 9, 4-20.

Dorozhkin, E. M., Kopnov, V. A., \& Romantsev, G. M. (2015). Multistage system of vocational pedagogical education. Proceedings of 2015. International Conference on Interactive Collaborative Learning, ICL 2015; Firenze; Italy; 20-24 September, pp. 725-728.

Fabrikov, M. S. (2015). The model of seniors' legal culture formation: the role of teacher. The world of science, culture, education, 4(53), 51-54.

Gimaliev, V. G., Prokopev, A. I., Makarova, E. V., Abdulkhakova, K. R., Kozin, M. N., \& Fazylzyanova, G. I. (2018). Personality features and values orientations of university students with manipulative behavior. Espacios, 39(20), 14.

Golovkin, R. B. (2013). Synthesis of innovative and traditional pedagogical technologies in teaching basic legal disciplines. Formation of knowledge, skills and professional competences of educational process of legal higher education institutions: materials of the All-Russian scientific and methodical conference, pp. 43-50.

Gunibsky, M. Sh. (2014). Innovative and interactive methods in the course of legal education. Legal world, 4, 40-44.

Gura, V. V. (2007). Theoretical bases of pedagogical projection of personal focused electronic educational resources and environment: PhD Abstract. Rostov-on-Don: Southern Federal University.

Hurst, C. (2017). Children Have the Capacity to Think Multiplicatively, as long as .... European Journal of STEM Education, 2(3), 07. https://doi.org/10.20897/ejsteme/78169

Hurst, C., \& Hurrell, D. (2016). Investigating Children's Multiplicative Thinking: Implications for Teaching. European Journal of STEM Education, 1(3), 56.

Ivanova, G. A. (2014). Features of the pedagogical personality of a higher school teacher as intellectuals of median type (to a question of training of jurists- mediators). Law and education, 2, 30-40.

Kuleshova, S. N. (2009). Criminalization of young people in the Russian society: sociocultural aspect (PhD Thesis). Stavropol: Stavropol State University.

Lomovtseva, N. V., Tchubarkova, E. V, \& Karasik, A. A. (2013). Fostering the Teachers Rediness for Using the Informational Educational Environment in Higher Scool. The Education and science journal, 1(3), 111-120.

Malysheva, I. V. (2015). The active and interactive forms of work when forming legal type of thinking. Bulletin of the Kuzbass institute, 3(24), 173-178.

Mashinyan, A. A., \& Kochergina, N. V. (2016). Principles and mechanisms of creation of distant comprehensive education environment. Open and distant education, 2(62), 19-32.

Mutavchi, E. P., Prokopyev, A. I., Kostyleva, G. V., Blinov, L. V., Fedorov, V. V., \& Polichka, A. E. (2018). Scientific - methodical resource of student training and vocational motivation development in university. Espacios, 39(20), 15.

Nesterenko, V. G., \& Matviyenko, L. M. (2016). Features and tendencies of education system development in Australia at a stage of teachers basic training. Alma mater (Bulletin of the high school), 10, 96-100.

Ozhiganova, M. V., Moskalenko, M. R., \& Bolgova, V. V. (2016). A Restorative Approach in Pedagogical and Preventive Work with Juvenile Offenders. IEJME-Mathematics Education, 11(8), 2800-2813. 
Petrova, E. V. (2015). To the question of the technique of teaching legal disciplines. Bulletin of science and education, 3(5), 154-158.

Pochinalina, L. N. (2007). Distance teaching: innovative projection of quality technology (by the example of discipline "Family law"): study guide. Moscow: Moscow state industrial university.

Polat, E. S., Moiseyeva, M. V., \& Petrov, A. E. (2006). Pedagogical technologies of distance learning: manual for students of higher educational institutions. Moscow: Academy.

Ryabchenko, O. N., Prokopev, A. I., Romanchenko, L. N., Korzhuev, A. V., Krokhina, Yu. A. (2018). Social and philosophical understanding of national and civic identity in the context of interethnic and interreligious conflict risks. XLinguae, 11(2), 359-369.

Shutova, V. N. (2016). Experience of application of interactive forms and methods in legal education. The modern problems of science and education, 4, 171-185.

Sivokon, E. E. Distant education. (2016). Retrieved from http:/ / kafitimpi.sfedu.ru/index.php?catid=29:2011-03-1311-10-42\&id=111:2011-04-18-06-23-44\&Itemid=42\&option=com_content\&view=article

Tkacheva, O. N., Simonova, M. V., \& Matveev, Y. V. (2016). The Model of Quality Assessment of a Scientific and Educational Network Performance. IEJME-Mathematics Education, 11(8), 2871-2883.

Turanin, V. Yu., \& Pogorelov, D. V. (2016). The possibilities of improving of legal disciplines teaching to students of non-legal specialties. Law and education, 4, 56-63.

Veledinskaya, S. B., \& Dorofeyeva, M. Yu. (2015). Mixed teaching: technology of educational process projection. Open and distant education, 2(58), 12-19.

\section{http://www.ejmste.com}

